MATEC Web of Conferences 6, 05006 (2013)

DOI: $10.1051 /$ matecconf/20130605006

(C) Owned by the authors, published by EDP Sciences, 2013

\title{
Influence of moisture on fire resistance of side-plated RC beams
}

\author{
J. Kolšek ${ }^{2}$, M. Saje ${ }^{1}$, I. Planinc ${ }^{1}$ and T. Hozjan ${ }^{1}$ \\ 1 University of Ljubljana, Faculty of Civil and Geodetic Engineering, Ljubljana, Slovenia \\ 2 ZAG - Slovenian National Building and Civil Engineering Institute, Ljubljana, Slovenia
}

\begin{abstract}
The objective of the paper is to present the effect of moisture in concrete on the fire resistance of side-plated reinforced concrete $(\mathrm{RC})$ beams. For this purpose an adequate new finite-element (FE) procedure is presented. The paper concludes with a parametric study, examining the impacts of the vapor-tight side plates, high initial moisture content and low initial permeability of concrete of the selected RC beam on the rate of the risk of concrete spalling.
\end{abstract}

\section{INTRODUCTION}

Plating techniques present a popular modern engineering solution of structural retrofitting. Until this time a broad range of different plating solutions has appeared in the market (i.e. the tension-face plating technique, the side-plating technique, the U wraps, etc.), nevertheless, in the engineering practice, the tension face plating solutions have been mostly implemented. A similar trend is detected in the published reports of the scientific investigations. So far, a vast amount of research has been executed on the tension face plated beams, but almost none has been dedicated to investigating structural behavior (especially such as in fire) of the alternatively plated (e.g. side-plated) beams.

Another problem which applies to any kind of concrete or composite concrete structure in fire is its thermal and mechanical damage, the former caused by the physical and chemical decomposition of the material at elevated temperatures, and the latter induced by the stresses due to restrained thermal dilatation or applied external mechanical loads. The higher the rate of concrete damage, the more deteriorated are the mechanical characteristics of the concrete (such as compressive strength and elastic modulus) and the more increased is the material permeability. In addition, the heterogeneity of concrete should be explicitly considered. Concrete consists of the solid matrix representing the hardened cement paste and aggregates as well as of pores. These are filled with water (liquid, adsorbed or chemically bound) and with the gaseous mixture of dry air and water vapor. Due to the presence of fluids inside the concrete pores and its pressure and concentration gradients, generated on account of phase transitions (water evaporation and vapor condensation) and concrete permeability gradients, mass fluxes of water and air inside the pores emerge and, consequently, the heat is not only conducted but also convected through the material. A part of the evoked mass fluxes shifts towards the heated surface of the body, while the rest moves inwards - towards the cooler layers, where vapor condenses and increases the level of pore saturation. As a consequence, the permeability of the material is substantially diminished in this region and speed of passing water and gas flows is reduced. The emerged clogged zone finally causes a rapid rise of pore pressures in front of the zone, accelerated crack propagation in this area and, in most severe cases, explosive spalling of the damaged material.

In scientific literature of the last decade, several mathematical models have been proposed for fire analyses of heterogeneous concrete structures. In general, two fundamental groups of such models can

This is an Open Access article distributed under the terms of the Creative Commons Attribution License 2.0, which permits unrestricted use, distribution, and reproduction in any medium, provided the original work is properly cited. 


\section{MATEC Web of Conferences}

be distinguished. The first group of these models are the models where "mechanical" (stress induced) damage effects are neglected in the heat and mass transfer inside the concrete element (e.g., [1]) and are, therefore, applicable for concrete structures with zero mechanical loading and where thermal dilatations of the concrete element are not (significantly) restrained, so that no (significant) stress is induced in the element during fire. In a general case of a mechanically loaded concrete structure in fire, however, the alternative fully coupled thermo-hygro-mechanical models must be applied (e.g. [4]). Unfortunately, extremely complex systems of governing equations and their respective constitutive relationships are usually observed in these sophisticated numerical models, which is why they are often reported as unmanageably time consuming and their applicability is limited (usually to specific problems with a small number of DOFs). As oppose to complex hydro-thermo-mechanical models, an empirically based approach for capturing the "mechanical" effects in a pure hygro-thermal model indirectly has been proposed by Dwaikat and Kodur [2].

In the present paper a new three-step numerical model for thermo-mechanically loaded sideplated RC beams is presented. The model consists of three mathematically uncoupled steps. In the first step, the fire scenario is proposed and the time-dependent change of temperatures in the fire compartment surrounding the structure is determined. In the following hygro-thermal step, the time and space distributions of temperatures are defined in the composite beam under analysis. Within this step, the simple well-known Fourier law of heat conduction is engaged for the non-porous steel sideplates, whereas for the porous heterogeneous RC beam a system of mass and energy conservation equations is implemented. These account for the porous and multiphase nature of concrete, its phase and chemical transformations, and mutual interactions between its thermal, hygral and (indirectly) mechanical degradation. The system of non-linear partial differential equations of the hygro-thermal step of the analysis is solved numerically by a Galerkin-type of FE method. In the final step of the fire analysis, we take a look into the stress-strain state evolution in the observed beam during fire. The side plates and the beam are here modeled by the geometrically and materially non-linear planar beam theory of Reissner. Special stress induced material properties such as viscous creep of steel and creep and transient deformations of concrete are considered explicitly and the kinematic hardening approach of cyclically loaded and reloaded material is considered. The final mixed system of non-linear algebraic and linear ordinary differential equations of the mechanical step of the analysis is solved numerically by a novel strain-based FE method. The paper concludes with a parametric study, examining the impacts of the vapour-tight side plates and of the mechanical stress distribution in the RC beam on the pore pressure build-up and, consequently, on the risk of concrete spalling.

\section{THERMO-HYGRO-MECHANICAL ANALYSIS OF A SIDE-PLATED RC BEAMS}

For the sake of simplicity, the standard ISO 834 fire curve is selected in this paper for the description of the time development of temperatures of the fire compartment (i.e. the first step of the analysis). In the second step, the coupled heat and mass transfer in the beam is observed by implementing the model of Davie et al. [1]. Additionally, the recommendations of Dwaikat and Kodur [2] are implemented in this step considering the thermal and mechanical damage dependent calculations of concrete permeability and predictions of concrete spalling. In the final step, the stress-strain evolution in the structure during fire is pursued. Within the second and the third step of the analysis, the total duration time of the fire is divided into time intervals $\left[t^{j-1}, t^{j}\right]$, and for each of the intervals the basic unknowns of the problem are iteratively determined.

\subsection{The heat and mass transfer submodel}

In the hygro-thermal submodel, we calculate time and space distributions of temperatures and pore pressures in the side-plated RC beam. For calculations of heat transfer in the steel side plates, we employ the simple Fourier law of heat conduction in solid homogeneous and nonporous materials, but the model 
of coupled heat and mass transfer by Davie et al. [1] is employed for the concrete part of the composite beam. The model of Davie [1] comprises three equations of mass conservation of free water, water vapour and dry air:

$$
\begin{gathered}
\frac{\partial\left(\overline{\rho_{F W}}\right)}{\partial t}=-\nabla \mathbf{J}_{F W}-\dot{E}_{F W}+\frac{\partial\left(\overline{\rho_{D}}\right)}{\partial t}, \\
\frac{\partial\left(\overline{\rho_{V}}\right)}{\partial t}=-\nabla \mathbf{J}_{V}+\dot{E}_{F W}, \\
\frac{\partial\left(\overline{\rho_{A}}\right)}{\partial t}=-\nabla \mathbf{J}_{A},
\end{gathered}
$$

and the equation of energy conservation:

$$
(\underline{\rho C}) \frac{\partial T}{\partial t}=-\nabla \cdot(-k \nabla T)-(\underline{\rho C \mathbf{v}}) \cdot \nabla T-\lambda_{E} \dot{E}_{F W}-\lambda_{D} \frac{\partial\left(\overline{\rho_{D}}\right)}{\partial t} .
$$

In Eqs. (1)-(2) the following denotations are engaged: $\mathbf{J}_{i}$ is the mass flux of phase $i, \rho_{i}$ is the mass concentration of phase $i$ (index $i$ represents phases of concrete: $F W$ is free water, $V$ is water vapor and $A$ is dry air), $E_{F W}$ is the rate of evaporation of free water (including desorption), $t$ is time, $\rho C$ is heat capacity of concrete, $k$ is its thermal conductivity, $\rho C v$ is the energy transferred by fluid flow, $\lambda_{E}$ is the specific heat of evaporation, $\lambda_{D}$ is specific heat of dehydration and $T$ is temperature. Furthermore, we express the mass fluxes $\mathbf{J}_{i}$ in terms of pressure and concentration gradients implementing the standard Darcy's and Fick's laws. These and all of the other constitutive equations, adopted in the proposed hygrothermal submodel, follow the recommendations of Davie et al. [1], however, an exception regarding the time dependent concrete permeability evaluations is made. While the case study of Davie $e$ t al. [1] deals with a problem, where zero "mechanical" effects in the pressure-driven flow evaluations are justifiably assumed, for a general case of a fire exposed RC beam, however, such an assumption is no longer valid, but the "mechanical" effects need to be explicitly considered instead. As recently proposed by Dwaikat and Kodur [2], in a pure hygro-thermal submodel this can be achieved by accounting for the gradients in the initial permeability of concrete, $k_{0}$ :

$$
k_{0}=k_{\text {top }}\left\{\begin{array}{ll}
10^{2 y / D} & y \leq x \\
10^{2 y / D}\left(10^{3(y-x) /(D-x)}\right) & y>x
\end{array}\right\} .
$$

In Eq. (3) $k_{\text {top }}$ denotes initial permeability in the top surface of the concrete section, $D$ is the depth of the concrete cross-section, $y$ is the distance from top of the cross-section, and $x$ is the depth of the neutral axis at service loads and ambient temperature. The equation was designed specifically for the evaluations of concrete permeability in flexural RC beams and was developed based on laboratory investigations of full-scale beams in ambient and fire conditions [2] as well as on the basic idea of the development of stress induced damage in concrete structures as accounted for in the sophisticated, fully (thermo-hygro-mechanically) coupled model by Gawin et al. (see, for example, [4]). In addition, the equation also accounts for the effect of curing of the RC beam while casting using burlap soaked with water on the top surface of the beam what reduces the evaporation of water from the top part of concrete and lowers the concrete permeability of this concrete area.

Moreover, at each time station $t>0$, the permeability of concrete, $k$, is changed additionally considering the current temperature of concrete, $T$, and the averaged pressure of liquids and gas inside the solid concrete matrix (i.e. pore pressure), $P_{\text {pore }}[2,3]$ :

$$
k=k_{0}\left[10^{0.0025\left(T-T_{0}\right)}\left(\frac{P_{\text {pore }}}{P_{0}}\right)^{0.368}\right] .
$$




\section{MATEC Web of Conferences}

In addition, concrete spalling evolution (if any) can be observed as well, implementing the empirically validated criterion [2]:

$$
\left.\Phi \cdot P_{\text {pore }}\right\rangle f_{t}(T)
$$

where $\Phi$ is porosity and $f_{t}(T)$ is tensile strength of concrete. According to this criterion, spalling is said to occur when the effective pore pressure exceeds the temperature dependent tensile strength of concrete. The solution of the presented hygro-thermal submodel is obtained numerically with a standard Galerkin's type of the finite element method (see Davie et al. [1]) and the temperature results along with the results for the spalled concrete areas are finally engaged as input data for the final, mechanical part of the fire analysis.

\subsection{The stress-strain evolution submodel}

Once the temperature and pore pressure variation in time and space has been obtained, the stress-strain state evolution in the beam during fire can be pursued. In the mechanical submodel both of the layers of the steel-concrete side-plated beam (i.e. the layer "a" representing the RC beam and the layer "b" representing the side plates, see Fig. 1) are modeled separately, each by the geometrically exact theory of a planar beam but neglecting the effects of shear deformations. The related governing equations of the ' $i$ ' $(i=\mathrm{a}, \mathrm{b})$ are:

$$
\begin{array}{clc}
\bullet \text { kinematic: } & \text { • equilibrium: } & \bullet \text { constitutive: } \\
1+u^{i \prime}-\left(1+\varepsilon^{i}\right) \cos \varphi^{i}=0, & R_{X}^{i^{\prime}}+P_{X}^{i}=0, & N^{i}=\int_{A_{x}^{i}} \sigma^{i}\left(D_{\sigma}^{i}, T\right) d A-N_{p}^{i}, \\
w^{i \prime}+\left(1+\varepsilon^{i}\right) \sin \varphi^{i}=0, & R_{Z}^{i^{\prime}}+P_{Z}^{i}=0, & M^{i}=\int_{A_{x}^{i}} z \sigma^{i}\left(D_{\sigma}^{i}, T\right) d A-M_{p}^{i} . \\
\varphi^{i \prime}-\kappa^{i}=0, & M^{i \prime}-\left(1+\varepsilon^{i}\right) Q^{i}+M_{Y}^{i}=0, &
\end{array}
$$

In Eqs. (6) the following notations are used: ( - )' is the derivative with respect to material coordinate $x, u^{\mathrm{i}}, w^{\mathrm{i}}$, and $\varphi^{\mathrm{i}}$ are, respectively, the $X$-displacement, the $Z$-displacement and the rotation of the reference axis of the layer " $i$ ", $\varepsilon^{\mathrm{i}}$ and $\kappa^{\mathrm{i}}$ are its extensional and bending strains, $R_{X}^{i}$ and $R_{Z}^{i}$ are the components of the cross-sectional stress-resultants with respect to the fixed basis $\left(\boldsymbol{E}_{X}, \boldsymbol{E}_{Y}, \boldsymbol{E}_{Z}\right)$ and $N^{i}, Q^{i}$, and $M^{i}$ are the cross-sectional axial force, the shear force and the bending moment. $R_{X}^{i}$ and $R_{Z}^{i}$ relate to $N^{i}$ and $Q^{i}$ as follows: $N^{i}=R_{X}^{i} \cos \varphi^{i}-R_{Z}^{i} \sin \varphi^{i}$ and $Q^{i}=R_{X}^{i} \sin \varphi^{i}+R_{Z}^{i} \cos \varphi^{i}$. Further, $\mathrm{P}_{x}^{i}, \mathrm{P}_{z}^{i}, \mathbf{M}_{y}^{i}$ are components of the traction vectors $\mathbf{P}^{i}$ and $\mathbf{M}^{i}$ representing static equivalents of surface and volume forces after being reduced with respect to the layer's reference axis, and $N_{p}^{i}$ and $M_{p}^{i}$ represent the contributions of pore pressures in the total stress of the layer " $i$ " (the well-known Terzaghi's principle). The latter equals to zero when the non-porous steel side plates are considered (i.e. for $i=b$ ). Furthermore, $\sigma^{i}$ and $D_{\sigma}^{i}$ are, respectively, the stress and the mechanical strain of a generic particle of the layer " $i$ ", and the relationship $\sigma^{i}\left(D_{\sigma}^{i}, T\right)$ is the material constitutive law of concrete/steel at elevated temperatures, in the proposed model taken as suggested by the Eurocode and additionally accounting for elastic reloading and kinematic hardening of cyclically loaded and reloaded material. Furthermore, within the time interval $j$, the mechanical strain of a generic particle, $D_{\sigma}^{i}$, is determined using the incremental equation:

$$
D^{i, j}=D^{i, j-1}+\Delta D^{i, j} .
$$

$D^{i, j}$ in Eq. (7) represents the increment of the total strain of the layer " $i$ " in the time interval " $j$ ". By implementing the principle of additivity of strains, we define that the strain increment, $\Delta D^{i, j}$, is the sum of the strain increments due to temperature, $\Delta D_{t h}^{i, j}$, stress, $\Delta D_{\sigma}^{i, j}$, creep, $\Delta D_{c r}^{i, j}$, and (for concrete only) transient strains, $\Delta D_{t r}^{i, j}$ (with $\Delta D_{t r}^{a, j} \neq 0$ and $\Delta D_{t r}^{b, j}=0$ ):

$$
\Delta D^{i, j}=\Delta D_{t h}^{i, j}+\Delta D_{\sigma}^{i, j}+\Delta D_{c r}^{i, j}+\Delta D_{t r}^{i, j} .
$$




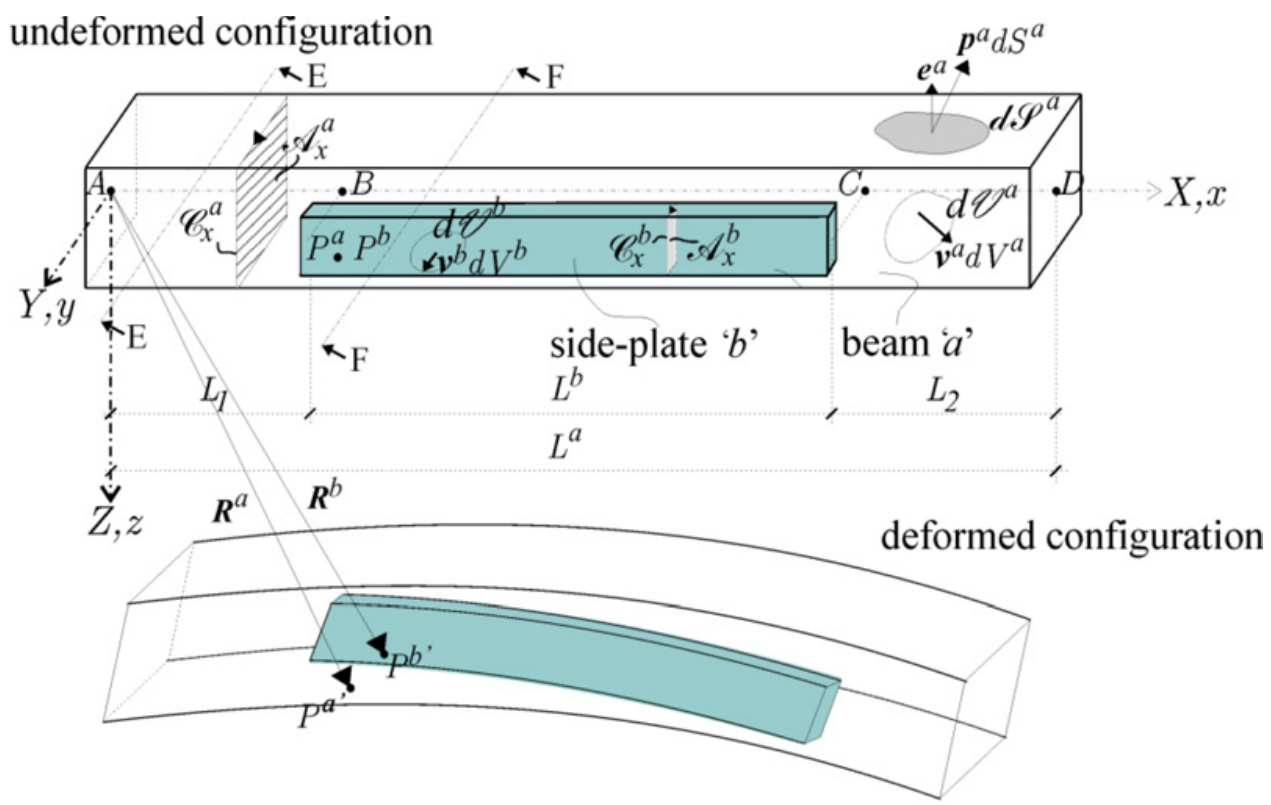

\section{cross-section E-E}

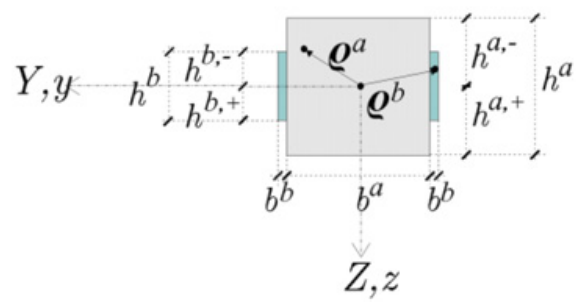

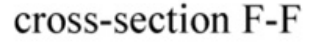

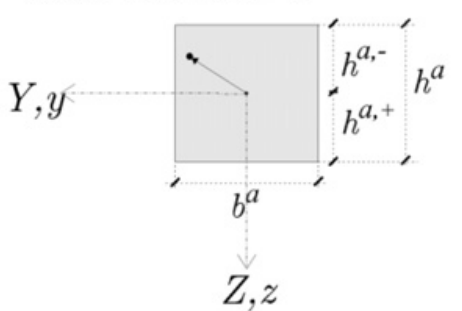

Figure 1. Undeformed and deformed configurations of a typical side-plated beam.

After decomposing the traction (load) vectors of both layers with respect to their external (index " $e$ ") and the contact (index " $c$ ") contributions:

$$
\mathbf{P}^{i}=\mathbf{P}_{e}^{i} \pm \mathbf{P}_{c}^{i} \text { and } \quad \mathbf{M}^{i}=\mathbf{M}_{e}^{i} \pm \mathbf{M}_{c}^{i},
$$

the equations of the side plates and the equations of the beam are finally coupled. The contact contributions, $\mathbf{P}_{c}^{i}$ and $\mathbf{M}_{c}^{i}$ (where $\mathbf{P}_{c}^{a}=-\mathbf{P}_{c}^{b}$ and $\mathbf{M}_{c}^{a}=-\mathbf{M}_{c}^{b}$ ), depend on the longitudinal $(\Delta U$ ) and transversal $(\Delta W)$ slips between the layers, i.e. $\mathbf{P}_{c}^{i}=f(\Delta U, \Delta W)$ and $\mathbf{M}_{c}^{i}=g(\Delta U, \Delta W)$, where $f$ and $g$ are functions determined by experiments for the actual type of the contact connection.

The final system of equations of the proposed mechanical submodel is solved numerically implementing the modified principle of virtual work and engaging a novel strain-based FE method. For a detailed description on the derivation and solving procedure of the model, the reader is referred to Kolšek et al. [7].

\section{THE CASE STUDY}

Let us consider a simply supported RC beam strengthened externally by two symmetrically bolted steel side plates and let us assume that the structure is exposed to mechanical and thermal loads simulating standard ISO 834 fire conditions. In this study a high strength concrete with extremely high initial 


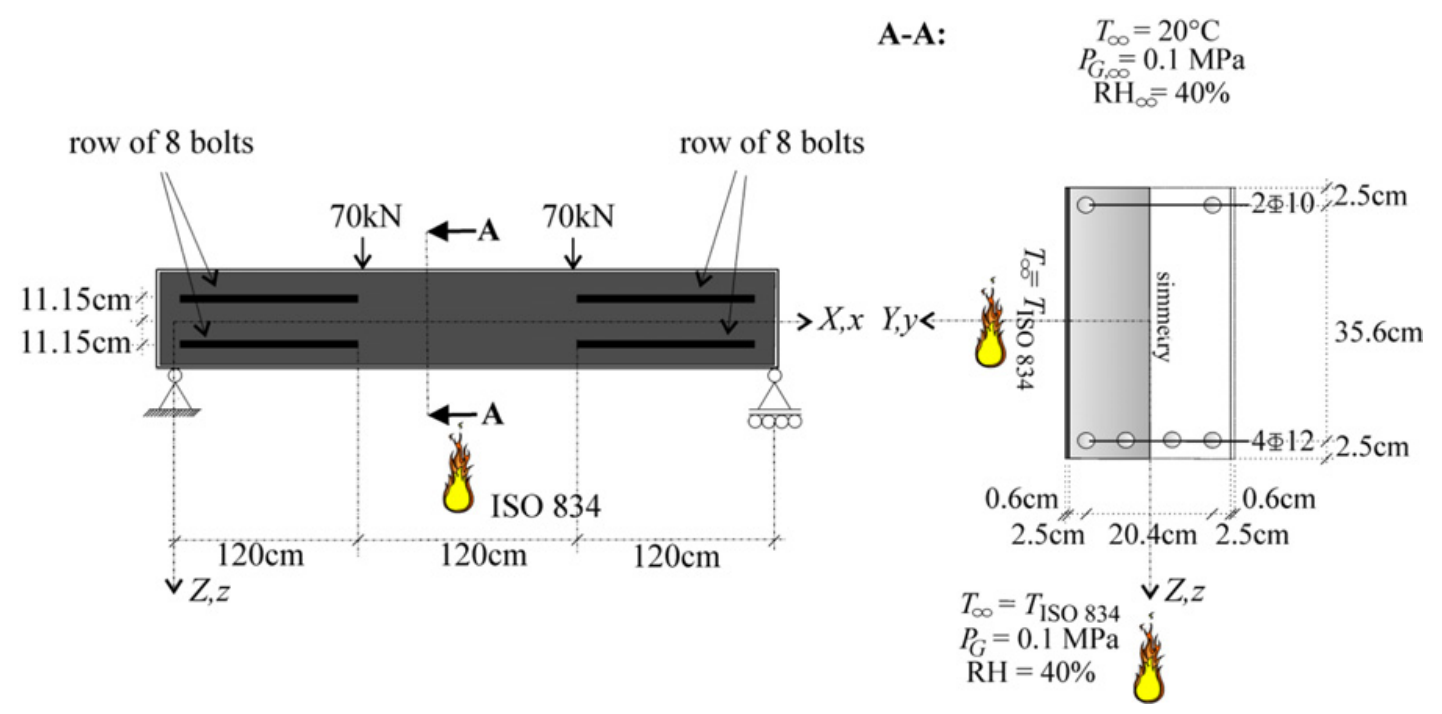

Figure 2. The fire analysis of a simply supported side-plated reinforced HSC beam: geometry and the boundary conditions employed in the numerical calculations of the heat and moisture fields.

moisture content will be taken into consideration representing a high risk for fire induced concrete spalling and the effect of the vapor tight side plates preventing the vapor from escaping the concrete will increase this risk additionally. The geometrical and loading data and the hygro-thermal boundary conditions are presented in Fig. 2. The rest of the input data are chosen as follows: initial relative humidity of air inside the concrete pores is $94 \%$, the surrounding air relative humidity is $40 \%$, initial porosity of concrete is $p_{\mathrm{or}, 0}=0.09$, the initial permeability in the top surface of the concrete section is $k_{\mathrm{top}}=5.10^{-23} \mathrm{~m}^{2}$, compressive strength of concrete at ambient temperature is $f_{\mathrm{c}, 20}=3.43 \mathrm{kN} / \mathrm{cm}^{2}$, elastic modulus of concrete at ambient temperature is $E_{\mathrm{c}, 20}=3250 \mathrm{kN} / \mathrm{cm}^{2}$, yield strength of steel at ambient temperature is $f_{\mathrm{ys}, 20}=33.5 \mathrm{kN} / \mathrm{cm}^{2}$, elastic modulus of steel at ambient temperature is $E_{\mathrm{ys}, 20}=$ $21200 \mathrm{kN} / \mathrm{cm}^{2}$, yield strength of reinforcing steel at ambient temperature is $f_{y a, 20}=53.7 \mathrm{kN} / \mathrm{cm}^{2}$, and elastic modulus of reinforcing steel at ambient temperature is $E_{\mathrm{ya}, 20}=18700 \mathrm{kN} / \mathrm{cm}^{2}$. The side plate$\mathrm{RC}$ beam connection is achieved through 2 parallel rows of 8 bolts at each end and each side of the beam. For the description of the mechanical response of each individual shear connector, the constitutive law of contact as suggested by Huang et al. [6] is integrated in the numerical analysis, where for the maximal bearing capacity of a shear connector at room temperature $P_{\max }=40 \mathrm{kN}$ is chosen.

In what follows, we take a brief look into the fire response of the presented structure. The area of spalled concrete at a specific time station is assessed using the criterion of Dwaikat and Kodur [2] (Eq. (5)). The current spalled area of the concrete cross-section is defined as the set of all finite elements, in which the selected spalling criterion (Eq. (5)) is met in all four Gaussian integration points of the element (Fig. 2). Since we assume that the embedment length of the bolts is sufficient, the separation of the spalled concrete is said to be prevented due to the attached side plates. Moreover, each time spalling takes place, the characteristics of the affected area of the cross-section change and the FE mesh of the cross-section should be reshaped in the mechanical subanalysis. To avoid numerically expensive remeshing, we assume only a very small strength of concrete in the affected area and we also consider small value of strength in the reinforcement bars, when the area of spalled concrete includes any of the reinforcement bars (observe the spalled concrete area at about $40 \mathrm{~min}$ after the onset of the fire in Fig. 3a). Along with the spalling scenario, the distributions of temperature and pore pressures over the cross section are presented in Fig. 3. 
(a) Temperatures $T\left[{ }^{\circ} \mathrm{C}\right]$ $10 \mathrm{~min} 30 \mathrm{~min} 60 \mathrm{~min}$
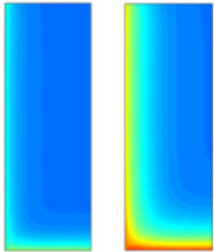

(b) Pore pressures $P_{\text {pore }}[\mathrm{MPa}]$

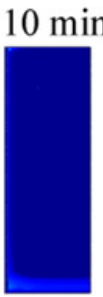

(c) Spalling scenario $20 \mathrm{~min} 30 \mathrm{~min} 45 \mathrm{~min}$
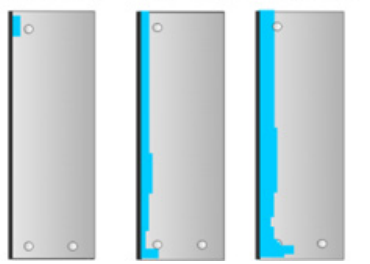

Figure 3. The time dependent: (a) distribution of temperatures $T$ (in ${ }^{\circ} \mathrm{C}$ ), (b) distribution of pore pressures $P_{\text {pore }}$ (in $\mathrm{MPa}$ ), and (c) predicted spalling scenario in a characteristic cross-section of the side-plated HSC beam.

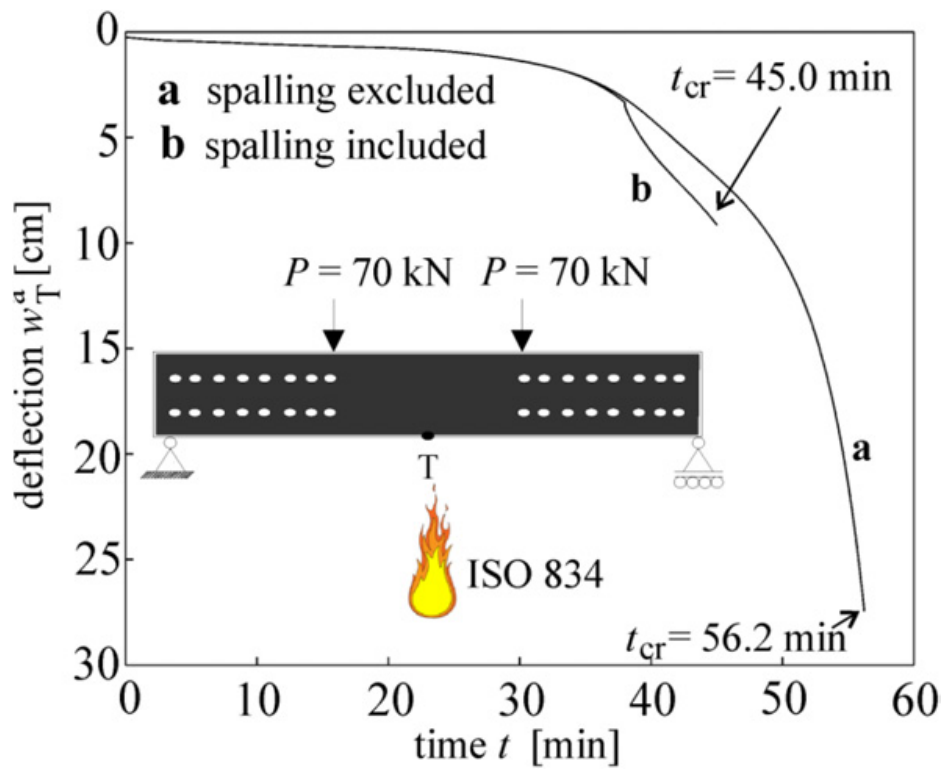

Figure 4. The mechanical response of the side-plated HSC beam: (a) concrete spalling is neglected, and (b) concrete spalling is considered.

In Fig. 4 we present the results of the mechanical analysis, where the midspan deflection-time curves of the unspalled and the spalled beam can be compared one to another. The effects of concrete spalling are here seen clearly, since they represent roughly $20 \%$ loss of the ultimate bearing capacity of the structure. In addition, the structure suffers from a decrease in ductility and its time of collapse.

\section{CONCLUSION}

In the paper a new finite-element model for fire analysis of steel-concrete side-plated beams has been proposed. The suggested numerical procedure has been performed in two separate steps, of which the moisture and heat transfer analysis step has been performed first, followed by the mechanical stressstrain analysis. For the calculation of moisture and heat transfer during fire the finite element model of Davie et al. [1] has been assumed and a novel, strain-based finite element formulation of the planar beam has been proposed in the mechanical analysis.

In the second part of the paper, the effect of concrete spalling in a fire-exposed side-plated reinforced HSC beam has been explored. Due to the mathematical separation of the "mechanical" and the 


\section{MATEC Web of Conferences}

"hygro-thermal" subanalyses, spalling, in general, could not be pursued automatically. Thus, an empirical formula of Dwaikat and Kodur [2] has been adopted in the hygrothermal analysis to account for the spalling effects indirectly. In the presented case study, a substantial effect of spalling on the bearing capacity has been reported resulting in a roughly $20 \%$ loss of the ultimate bearing capacity of the structure and a substantial decrease in ductility of its mechanical response.

\section{References}

[1] Davie C.T., Pearce C.J., Bićanić N., Coupled heat and moisture transport in concrete at elevated temperatures - Effects of capillary pressure and adsorbed water. Numerical Heat Transfer, Part A: Applications, 49 (8), 733-763, 2006.

[2] Dwaikat M. B., Kodur V. K. R., Fire induced spalling in high strength concrete beams. Fire Technology, 46 (1), 251-274, 2010.

[3] Gawin D., Pesavento F., Schrefler B.A. Simulation of damage-permeability coupling in hygrothermomechanical analysis of concrete at high temperature. Communications in Numerical Methods in Engineering, 18 (2), 113-119, 2002.

[4] Gawin D., Pesavento F., Schrefler B.A. Modelling of hygro-thermal behaviour of concrete at high temperature with thermo-chemical and mechanical material degradation. Computational Methods in Applied Mechanics and Engineering, 192 (13-14), 1731-1771, 2003.

[5] Hozjan T., Saje M., Srpčič S., Planinc I. Fire analysis of steel-concrete composite beam with interlayer slip. Computers and Structures, 89 (1-2), 189-200, 2011.

[6] Huang Z., Burgess I., Plank R. The influence of shear connectors on the behavior of composite steel-framed buildings in fire. Journal of Constructional Steel Research 51 (3) 219-237, 1999.

[7] Kolšek J., Hozjan T., Saje M., Planinc I. The fire analysis of a steel-concrete side-plated beam. Finite Elements in Analysis and Design, submitted. 